\title{
Rhodium-catalyzed C-H functionalization of heteroarenes using indoleBX hypervalent iodine reagents
}

\author{
Erwann Grenet, Ashis Das, Paola Caramenti and Jérôme Waser ${ }^{*}$
}

\section{Letter}

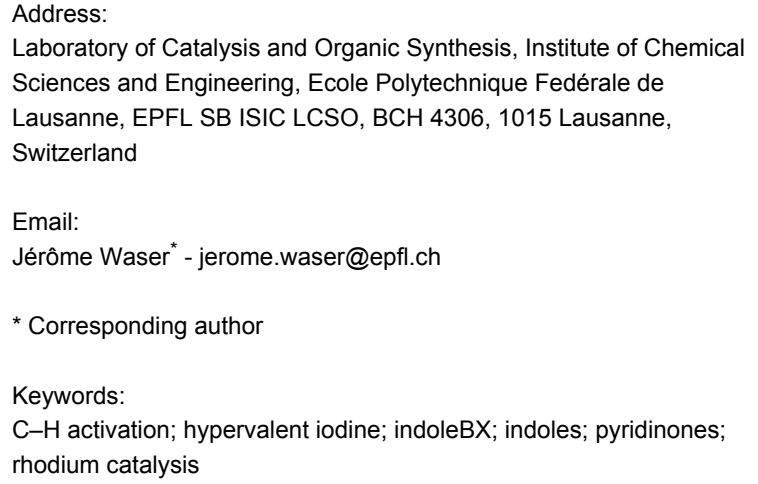

Beilstein J. Org. Chem. 2018, 14, 1208-1214.

doi:10.3762/bjoc.14.102

Received: 07 March 2018

Accepted: 09 May 2018

Published: 25 May 2018

This article is part of the Thematic Series "Hypervalent iodine chemistry in organic synthesis".

Guest Editor: T. Wirth

(C) 2018 Grenet et al.; licensee Beilstein-Institut. License and terms: see end of document.

\begin{abstract}
The $\mathrm{C}-\mathrm{H}$ indolation of heteroarenes was realized using the benziodoxolone hypervalent iodine reagents indoleBXs. Functionalization of the $\mathrm{C}-\mathrm{H}$ bond in bipyridinones and quinoline $\mathrm{N}$-oxides catalyzed by a rhodium complex allowed to incorporate indole rings into aza-heteroaromatic compounds. These new transformations displayed complete regioselectivity for the C-6 position of bipyridinones and the C-8 position of quinoline $N$-oxides and tolerated a broad range of functionalities, such as halogens, ethers, or trifluoromethyl groups.
\end{abstract}

\section{Introduction}

Nitrogen-containing heteroaromatic compounds have valuable properties in medicinal chemistry, pharmacology and functional materials. Among those, pyridinone, sometimes called pyridone, is a key structural motif of well-known active compounds and natural products (Figure 1) [1]. For example, the 2-pyridinone ring is present in milrinone (1), used to treat heart failure, while a 4-pyridinone is part of mimosine (2), an alkaloid isolated from Mimosa pudica. A benzene-fused pyridinone - a quinolone - can be found in brexpiprazole (3), a drug used against schizophrenia. In addition, the indole core is also omnipresent in bioactive compounds [2]. It can be directly bound to other heterocycles, such as a dihydropyrazidinone in hamacanthine A (4) (Figure 1) [3]. Due to their occurrence in biologically active compounds, it is therefore attractive to develop new methods to functionalize pyridinones. The introduction of further heterocyclic rings, such as indoles, is particularly attractive.

Most of the methods for indolylpyridinone synthesis involve a condensation cascade process to generate the pyridinone ring [4-6]. These methods usually require an electron-withdrawing group (nitrile, nitro, carbonyl), which ends up on the pyridi- 
<smiles>Cc1[nH]c(=O)c(C#N)cc1-c1ccncc1</smiles>

milrinone (1)<smiles>N[C@@H](Cn1ccc(=O)c(O)c1)C(=O)O</smiles>

mimosine (2)<smiles>O=c1ccc2ccc(OCCCCN3CCN(c4cccc5sccc45)CC3)cc2[nH]1</smiles>

brexpiprazole (3)<smiles>O=C1NC(c2c[nH]c3cc(Br)ccc23)CN=C1c1c[nH]c2cc(Br)ccc12</smiles>

hamacanthin A (4)

Figure 1: Bioactive compounds with pyridinone, quinolone and indole cores.

none ring. As alternative, a Suzuki-Miyaura coupling between 3-halogenoindoles and (2-methoxypyridyl)boronic acids followed by a deprotection of the methoxy group $[7,8]$ or transition-metal-catalyzed annulation methods [9] have also been reported.

In contrast, several procedures have been described for the modification of pyridinones to introduce other substituents, especially based on highly efficient $\mathrm{C}-\mathrm{H}$ functionalization methods [10]. Very recently, several research groups have selectively functionalized the $\mathrm{C}-6 \mathrm{C}-\mathrm{H}$ bond by using a 2-pyridyl directing group on the nitrogen and a transition metal catalyst (reaction 1, Scheme 1A) [11-19]. In particular, Li and co-workers have used ethynylbenziodoxolone (EBX) hypervalent iodine reagents to achieve a regiodivergent alkynylation of the pyridinone core employing either a gold(I) or a rhodium(III) catalyst for C-5 and C-6 functionalization, respectively [13]. Hypervalent iodine reagents in general [20], and benziodoxole derivatives in particular [21], have found broad application in synthetic chemistry. Aryl iodonium salts have been used successfully in transition-metal-catalyzed transformations [22], but only one application of indole iodonium salts in copper catalysis by You and co-workers had been reported until 2017 [23]. In this context, indole-based benziodoxole hypervalent iodine reagents, recently introduced by Yoshikai's and our group [2427], appeared ideal partners to develop a new $\mathrm{C}-\mathrm{H}$ heteroarylation of pyridinones.

Herein, we report the selective $\mathrm{C}-\mathrm{H}$ heteroarylation of the C-6 position of bipyridinones by a rhodium-catalyzed reaction with indoleBX (reaction 2, Scheme 1A). In addition, we demonstrate that the mild conditions developed allow the heteroarylation of the C- 8 position of quinoline $N$-oxides, whereas formation of the quinolinone had been observed in our previous work (Scheme 1B). The obtained products combine up to three classes of privileged heterocycles in medicinal chemistry in a

\section{A) $\mathrm{C}-6 \mathrm{C}-\mathrm{H}$ functionalization of pyridinones}
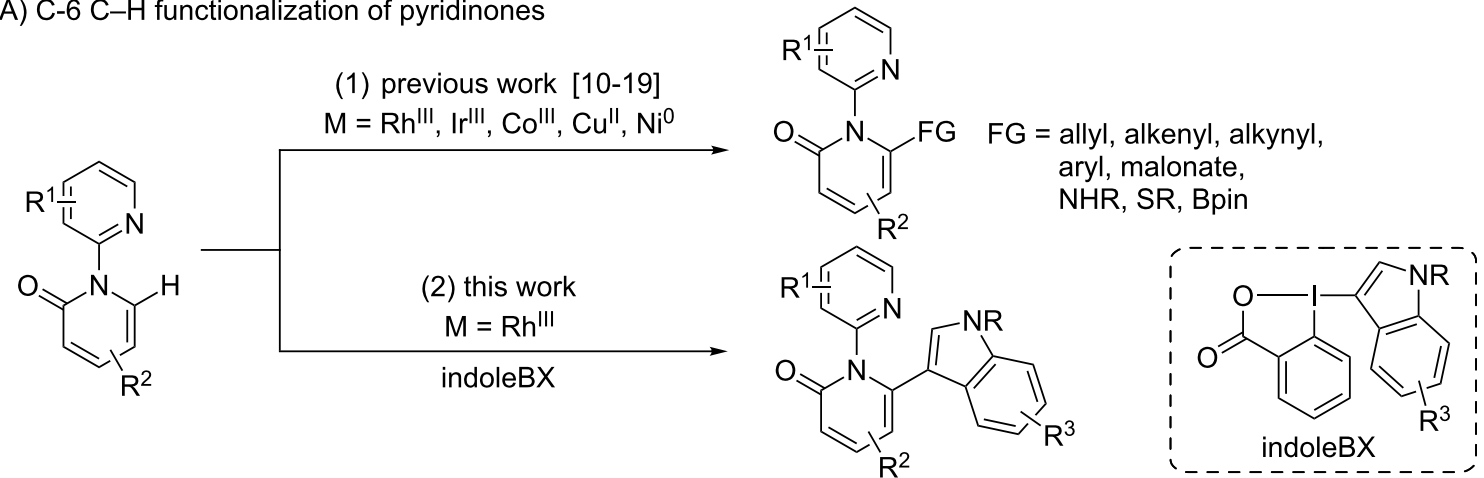

B) $\mathrm{C}-8 \mathrm{C}-\mathrm{H}$ heteroarylation of quinoline $\mathrm{N}$-oxides<smiles>[R]c1ccc2ccc(=O)[nH]c2c1-c1c[nH]c2ccccc12</smiles>

(3) previous work in our group [24]

indoleBX<smiles></smiles> 
single compound, and are therefore expected to be highly useful building blocks in the search for new bioactive compounds.

\section{Results and Discussion}

We started the studies on $\mathrm{C}-\mathrm{H}$ indolation with the optimization of the reactions conditions (Table 1 ) for the coupling of $\left[1,2^{\prime}-\right.$ bipyridin]-2-one (5a) with Me-indoleBX 6a, easily obtained from commercially available 1-methylindole and 2-iodobenzoic acid [24]. While the reaction conditions previously developed in our group for the $\mathrm{C}-\mathrm{H}$ functionalization of 2-phenylpyridine [24] failed for the coupling of 5a with 6a (Table 1, entry 1$)$, we were pleased to see that addition of 0.15 equiv $\mathrm{Zn}(\mathrm{OTf})_{2}$ allowed a full conversion to the desired product $7 \mathbf{a}$ in $86 \%$ yield (Table 1 , entry 2 ). The Lewis acid is supposed to weaken the $\mathrm{O}-\mathrm{I}$ bond by coordination of the carboxy group in 6a. No base was required in this case. The reaction was completely selective for the C-6 position of the pyridinone ring. Control experiments pointed out that both Lewis acid (Table 1, entry 3 ) and $\mathrm{AgSbF}_{6}$ as additive (Table 1, entry 4) were necessary for an efficient reaction. The transformation was tolerant to air (Table 1, entry 5). However, more byproducts were observed. Decreasing the temperature (Table 1, entry 6) or the catalyst loading (Table 1, entry 7) resulted in lower yields. Finally, three control experiments with 1-methylindole (8, Table 1, entry 8), 3-iodo-1-methylindole (9, Table 1, entry 9) and the poorly stable $(1 H$-indol-3-yl)(phenyl)iodonium tetrafluoroborate [23] (10, Table 1, entry 10) did not lead to the formation of 7a, highlighting the unique reactivity of the benziodoxolone hypervalent iodine reagent.

The scope and limitations of the reaction were then studied (Scheme 2). The diversification of the directing group was examined first. The unsubstituted pyridine group led to the formation of product $7 \mathbf{a}$ in $86 \%$ yield. The electron-rich 5-methoxypyridine and the electron-poor 5-trifluoromethylpyridine directing groups gave products $7 \mathbf{b}$ and $7 \mathbf{c}$ in $82 \%$ and $72 \%$ yield, respectively. When a nitro group was present on the pyridine (5d), the product was not observed, probably due to a weaker coordination of the nitrogen on the pyridine. Pyrimidine could not be used as directing group (5e), confirming what has already been reported by others authors [13]. Quinoline 7f was obtained in $79 \%$ yield. Concerning the pyridinone core, both an electron-donating methyl group and electron-withdrawing trifluoromethyl and fluoro groups $(\mathbf{7 g - i})$ were well tolerated in the $\mathrm{C}-3$ position. However, the strong electron-withdrawing $\mathrm{CF}_{3}$ group resulted in a lower $65 \%$ yield $(7 \mathbf{h})$. This observation is also true for the $\mathrm{C}-4$ position. Indeed, products $\mathbf{7 j - 1}$ were synthesized in 78\% yield for a methyl, $66 \%$ yield for a trifluoromethyl and $84 \%$ yield for a benzyloxy substituent. As previously reported [13], 5-substituted pyridinone $\mathbf{5 m}$ could not

Table 1: Optimization of the $\mathrm{C}-\mathrm{H}$ heteroarylation ${ }^{\mathrm{a}, \mathrm{b}}$<smiles>O=c1ccccn1-c1ccccn1</smiles>

$5 \mathbf{a}$

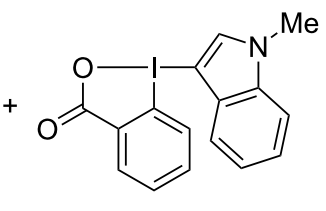

$6 a$

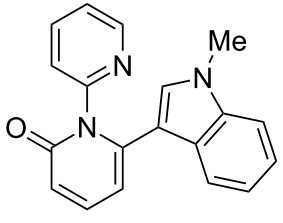

$7 \mathbf{a}$

\begin{tabular}{|c|c|c|}
\hline Entry & Changes from conditions & Yield (\%) \\
\hline 1 & $\begin{array}{l}{\left[\mathrm{RhCp}^{\star} \mathrm{Cl}_{2}\right]_{2}(2.5 \mathrm{~mol} \%)} \\
\mathrm{AgSbF}_{6}(0.10 \text { equiv }) \\
\text { NaOPiv }(0.10 \text { equiv }) \\
\text { DCE, } 12 \mathrm{~h}, 50^{\circ} \mathrm{C}\end{array}$ & no reaction \\
\hline 2 & - & 86 \\
\hline 3 & without $\mathrm{Zn}(\mathrm{OTf})_{2}$ & no reaction \\
\hline 4 & without $\mathrm{AgSbF}_{6}$ & 60 \\
\hline 5 & under air atmosphere & 80 \\
\hline 6 & $60{ }^{\circ} \mathrm{C}$ & 48 \\
\hline 7 & $1 \mathrm{~mol} \%$ of $\left[\mathrm{RhCp}^{*} \mathrm{Cl}_{2}\right]_{2}$ & 75 \\
\hline 8 & 1-methylindole (8) & no reaction \\
\hline 9 & 3-iodo-1-methylindole (9) & $0^{\mathrm{C}}$ \\
\hline 10 & iodonium salt 10 & $0^{c}$ \\
\hline
\end{tabular}

aReactions conditions: 5 (0.20 mmol), 6 (0.20 mmol), $\left[\mathrm{RhCp}^{*} \mathrm{Cl}_{2}\right]_{2}(3.7 \mathrm{mg}, 6.0 \mu \mathrm{mol}, 3 \mathrm{~mol} \%), \mathrm{AgSbF}_{6}(10.3 \mathrm{mg}, 30.0 \mu \mathrm{mol}, 0.15 \mathrm{equiv}), \mathrm{Zn}(\mathrm{OTf})_{2}$ $\left(10.9 \mathrm{mg}, 30.0 \mu \mathrm{mol}, 0.15\right.$ equiv), methanol $(2.0 \mathrm{~mL})$ at $80^{\circ} \mathrm{C}$ for $12 \mathrm{~h}$. ' Isolated yield after preparative TLC. 'Decomposition. 
<smiles>[R]c1ccc(=O)n(-c2cc[R]#cn2)c1</smiles>

5<smiles>[R3]c1ccc2c(I)cn([R4])c2c1</smiles>

$\left[\mathrm{RhCp}^{*} \mathrm{Cl}_{2}\right]_{2}(3 \mathrm{~mol} \%)$,

$\mathrm{AgSbF}_{6}$ (0.15 equiv),

$\mathrm{Zn}(\mathrm{OTf})_{2}$ ( 0.15 equiv)

$\mathrm{MeOH}(0.1 \mathrm{M})$,

$\mathrm{N}_{2}, 12 \mathrm{~h}, 80^{\circ} \mathrm{C}$<smiles>[R]C=Cc1cccc(=O)n1-c1ccc([R])cc1</smiles><smiles>Cn1cc(-c2cccc(=O)n2-c2ccccn2)c2ccccc21</smiles>

$7 a, 86 \%$<smiles></smiles>

$7 b, 82 \%$<smiles>Cn1cc(-c2cccc(=O)n2-c2ccc(C(F)(F)F)cn2)c2ccccc21</smiles>

7c, $72 \%$<smiles>Cn1cc(-c2cc3ccccc3c(=O)n2[18O])c2ccccc21</smiles>

7n, $82 \%$<smiles>Cn1cc(-c2cccc(=O)n2-c2ccc3ccccc3n2)c2ccccc21</smiles>

7f, $79 \%$<smiles>Cn1cc(-c2cc(=O)ccn2[18O])c2ccccc21</smiles>

7o, $57 \%$<smiles>[R]c1cc(-c2cn(C)c3ccccc23)n([R20])c(=O)c1</smiles>

$\mathrm{R}^{2}=\mathrm{Me}, \mathbf{7 j}, 78 \%$

$\mathrm{CF}_{3,7 \mathrm{k}, 66 \%}$

OBn, $71,84 \%$
F, $7 \mathbf{i}, 75 \%$<smiles></smiles>

$7 q, 76 \% \mathrm{Br}$<smiles>[R10]n1c(-c2c[nH]c3ccccc23)cccc1=O</smiles>

7r, $84 \%$<smiles>[R17]n1c(-c2c[nH]c3cc(Br)ccc23)cccc1=O</smiles>

7s, $77 \%$

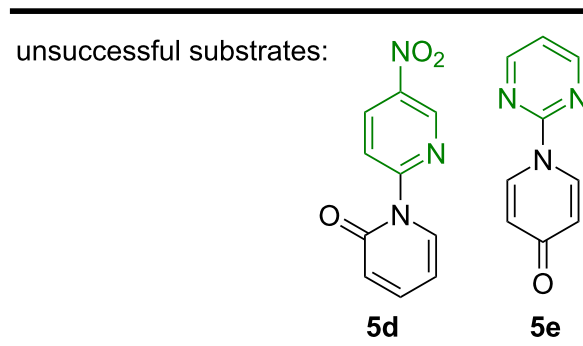<smiles>Cc1ccc(=O)n(-c2ccccn2)c1</smiles>

$5 \mathrm{~m}$<smiles>O=c1cnccn1-c1ccccn1</smiles>

$5 p$

Scheme 2: Scope and limitations of the Rh-catalyzed C-H activation of [1,2'-bipyridin]-2-one.

be functionalized. Isoquinolone $\mathbf{7 n}$ was prepared in $82 \%$ yield. The methodology could also be applied to 4-pyridone in a moderate $57 \%$ yield for product $\mathbf{7 0}$. Unfortunately, pyrazin-2-one $\mathbf{5 p}$ could not be functionalized. Modification of the hypervalent iodine reagent was then investigated with three selected compounds only. A bromo substituent on the benzene ring was well tolerated (7q). The coupling could be also performed with $\mathrm{N}-\mathrm{H}$ unprotected indoleBX reagents to afford products $7 \mathbf{r}$ and $7 \mathbf{s}$ in $84 \%$ and $77 \%$ yield, respectively.
We also applied these conditions to different quinoline $N$-oxides (Scheme 3). This class of substrates had also been used for $\mathrm{C}-\mathrm{H}$ alkynylation using EBX reagents [28]. During our previous work, we had attempted the C8-heteroarylation of quinoline $\mathrm{N}$-oxide with Me-indoleBX 6a. However, the transformation required a temperature of $100{ }^{\circ} \mathrm{C}$, leading to the formation of the corresponding isoquinolone in only $38 \%$ yield [24]. By employing the milder conditions developed for pyridinones, we were pleased to see that the $\mathrm{N}$-oxide group could be preserved and 


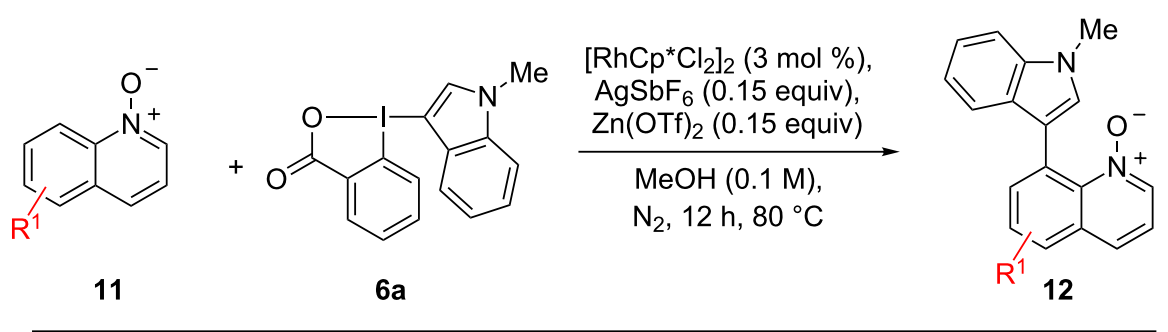<smiles>Cn1cc(-c2cccc3ccc[n+]([O-])c23)c2ccccc21</smiles>

$12 a, 60 \%$<smiles>Cc1ccc2cccc(-c3cn(C)c4ccccc34)c2[n+]1[O-]</smiles>

$12 b, 66 \%$<smiles>COc1cc(-c2cn(C)c3ccccc23)c2c(ccc[n+]2[O-])c1</smiles>

$12 c, 57 \%$<smiles>Cn1cc(-c2cc(-c3ccccc3)cc3ccc[n+]([O-])c23)c2ccccc21</smiles>

12d, $73 \%$

Scheme 3: Scope of the Rh-catalyzed peri $\mathrm{C}-\mathrm{H}$ activation of quinoline $\mathrm{N}$-oxides.

product 12a was obtained in $60 \%$ yield. A methyl substitution in $\mathrm{C}-2$ position gave the product $\mathbf{1 2 b}$ in $66 \%$ yield. In C-6 position both a methoxy and a phenyl group were well tolerated giving $57 \%$ and $73 \%$ yield of products $\mathbf{1 2 c}$ and $\mathbf{1 2 d}$.

The pyridine directing group could be cleaved by alkylation of the pyridine nitrogen using methyl triflate followed by reduction with sodium cyanoborohydride to deliver the $\mathrm{N}-\mathrm{H}$ unprotected pyridinone $\mathbf{1 3}$ in $\mathbf{7 4 \%}$ yield (Scheme 4) [29]. A rearrangement of the $\mathrm{N}$-oxide furnished the corresponding isoquinolone $\mathbf{1 4}$ in $62 \%$ yield.

\section{Conclusion}

In summary, we have developed the C-6 selective $\mathrm{C}-\mathrm{H}$ heteroarylation of pyridin-2-ones using indoleBXs as coupling partners, $\left[\mathrm{RhCp} * \mathrm{Cl}_{2}\right]_{2}$ as catalyst, $\mathrm{AgSbF}_{6}$ as co-catalyst and
$\mathrm{Zn}(\mathrm{OTf})_{2}$ as Lewis acid. The reaction could also be applied to functionalize one pyridin-4-one in C-6 position, one isoquinolinone in $\mathrm{C}-3$ position and quinoline $\mathrm{N}$-oxides in C-8 position. After cleavage of the directing group or rearrangement of the $\mathrm{N}$-oxide function, we were able to access 6-(indol-3-yl)pyridinone and 8-(indol-3-yl)quinolone. The developed transformations give access to important heterocyclic building blocks for synthetic and medicinal chemistry and set the stages for the development of other $\mathrm{C}-\mathrm{H}$ heteroarylation processes based on indoleBX reagents.

\section{Experimental}

\section{General procedure for $\mathrm{C}-\mathrm{H}$ heteroarylation}

In a sealed tube, $\left[\mathrm{RhCp}^{*} \mathrm{Cl}_{2}\right]_{2}(3.7 \mathrm{mg}, 6.0 \mu \mathrm{mol}, 3 \mathrm{~mol} \%)$, $\mathrm{AgSbF}_{6}\left(10.3 \mathrm{mg}, 30.0 \mu \mathrm{mol}, 0.15\right.$ equiv), $\mathrm{Zn}(\mathrm{OTf})_{2}(10.9 \mathrm{mg}$, $30.0 \mu \mathrm{mol}, 0.15$ equiv), the corresponding pyridinone or quino-
(1)<smiles>Cn1cc(-c2cccc(=O)n2-c2ccccn2)c2ccccc21</smiles>

$7 a$<smiles>Cn1cc(-c2cccc3ccc[n+]([O-])c23)c2ccccc21</smiles>

$12 a$

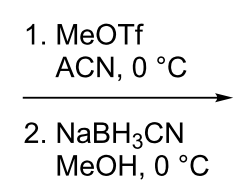<smiles>Cn1cc(-c2cccc(=O)[nH]2)c2ccccc21</smiles>

$13,74 \%$ yield

TFAA, DMF, rt<smiles>Cn1cc(-c2cccc3ccc(=O)[nH]c23)c2ccccc21</smiles>

$14,62 \%$ yield 
line $N$-oxide ( $0.20 \mathrm{mmol}, 1.00$ equiv) and the corresponding hypervalent iodine reagent $(0.20 \mathrm{mmol}, 1.00$ equiv $)$ were solubilized in dry $\mathrm{MeOH}(2.0 \mathrm{~mL}, 0.1 \mathrm{M})$ under $\mathrm{N}_{2}$ atmosphere. The mixture was stirred at $80^{\circ} \mathrm{C}$ for $12 \mathrm{~h}$. The mixture was then diluted with DCM $(5 \mathrm{~mL})$ and quenched with a saturated aqueous solution of $\mathrm{NaHCO}_{3}(5 \mathrm{~mL})$. The two layers were separated and the aqueous layer was extracted twice with DCM $(5 \mathrm{~mL})$. The organic layers were combined, dried over magnesium sulfate dehydrate, filtered and concentrated under reduced pressure. The crude residue was purified by preparative TLC using $\mathrm{DCM} / \mathrm{MeOH}$ to afford the pure desired compound.

\section{Supporting Information}

\section{Supporting Information File 1}

Detailed experimental procedures, analytical data for all compounds and copies of the NMR spectra of new compounds.

[https://www.beilstein-journals.org/bjoc/content/ supplementary/1860-5397-14-102-S1.pdf]

\section{Acknowledgements}

This work is supported by the ERC starting grant 334840 , iTools4MC, by the Swiss National Science Foundation (No. 200021_159920), the COST action CA15106 (C-H Activation in Organic Synthesis, CHAOS) and EPFL.

\section{ORCID ${ }^{\circledR}$ iDs}

Erwann Grenet - https://orcid.org/0000-0002-5249-8766 Jérôme Waser - https://orcid.org/0000-0002-4570-914X

\section{References}

1. Jessen, H. J.; Gademann, K. Nat. Prod. Rep. 2010, 27, 1168-1185. doi:10.1039/b911516c

2. Gribble, G. W. Indole Ring Synthesis: From Natural Products to Drug Discovery; John Wiley \& Sons: Chichester, 2016.

3. Gunasekera, S. P.; McCarthy, P. J.; Kelly-Borges, M. J. Nat. Prod. 1994, 57, 1437-1441. doi:10.1021/np50112a014

4. Mohamed, S. F.; Hosni, H. M.; Amr, A. E.; Abdalla, M. M. Russ. J. Gen. Chem. 2016, 86, 672-680. doi:10.1134/S1070363216030269 See for a C-4 substituted example.

5. Krichevskii, É. S.; Alekseeva, L. M.; Kuleshova, E. F.; Granik, V. G. Pharm. Chem. J. 1995, 29, 132-133. doi:10.1007/BF02226526 See for a $\mathrm{C}-5$ substituted example.

6. El-Sayed, N. S.; Shirazi, A. N.; El-Meligy, M. G.; El-Ziaty, A. K.; Rowley, D.; Sun, J.; Nagib, Z. A.; Parang, K. Tetrahedron Lett. 2014, 55, 1154-1158. doi:10.1016/j.tetlet.2013.12.081 See for a C-6 substituted example.
7. Chen, K. X.; Vibulbhan, B.; Yang, W.; Sannigrahi, M.; Velazquez, F.; Chan, T.-Y.; Venkatraman, S.; Anilkumar, G. N.; Zeng, Q.; Bennet, F.; Jiang, Y.; Lesburg, C. A.; Duca, J.; Pinto, P.; Gavalas, S.; Huang, Y.; Wu, W.; Selyutin, O.; Agrawal, S.; Feld, B.; Huang, H.-C.; Li, C.; Cheng, K.-C.; Shih, N.-Y.; Kozlowski, J. A.; Rosenblum, S. B.; Njoroge, F. G. J. Med. Chem. 2012, 55, 754-765. doi:10.1021/jm201258k See for a C-3 example.

8. Kaila, N.; Follows, B.; Leung, L.; Thomason, J.; Huang, A.; Moretto, A.; Janz, K.; Lowe, M.; Mansour, T. S.; Hubeau, C.; Page, K.; Morgan, P.; Fish, S.; Xu, X.; Williams, C.; Saiah, E. J. Med. Chem. 2014, 57, 1299-1322. doi:10.1021/jm401509e

9. Krieger, J.-P.; Lesuisse, D.; Ricci, G.; Perrin, M.-A.; Meyer, C.; Cossy, J. Org. Lett. 2017, 19, 2706-2709. doi:10.1021/acs.orglett.7b01051

10. Hirano, K.; Miura, M. Chem. Sci. 2018, 9, 22-32. doi:10.1039/c7sc04509c

11. Odani, R.; Hirano, K.; Satoh, T.; Miura, M. Angew. Chem., Int. Ed. 2014, 53, 10784-10788. doi:10.1002/anie.201406228

12. Miura, W.; Hirano, K.; Miura, M. J. Org. Chem. 2017, 82, 5337-5344. doi:10.1021/acs.joc.7b00682 and references cited therein.

13. Li, Y.; Xie, F.; Li, X. J. Org. Chem. 2016, 81, 715-722. doi:10.1021/acs.joc.5b02410

14. Kong, L.; Yu, S.; Tang, G.; Wang, H.; Zhou, X.; Li, X. Org. Lett. 2016, 18, 3802-3805. doi:10.1021/acs.orglett.6b01806

15. Peng, P.; Wang, J.; Jiang, H.; Liu, H. Org. Lett. 2016, 18, 5376-5379. doi:10.1021/acs.orglett.6b02755

16. Das, D.; Poddar, P.; Maity, S.; Samanta, R. J. Org. Chem. 2017, 82, 3612-3621. doi:10.1021/acs.joc.7b00135

17. Kumar, K. A.; Kannaboina, P.; Das, P. Org. Biomol. Chem. 2017, 15, 5457-5461. doi:10.1039/c7ob01277b

18. Wang, H.; Pesciaioli, F.; Oliveira, J. C. A.; Warratz, S.; Ackermann, L. Angew. Chem., Int. Ed. 2017, 56, 15063-15067. doi:10.1002/anie.201708271

19. Das, D.; Samanta, R. Adv. Synth. Catal. 2018, 360, 379-384. doi:10.1002/adsc.201701244 and references cited therein.

20. Yoshimura, A.; Zhdankin, V. V. Chem. Rev. 2016, 116, 3328-3435. doi:10.1021/acs.chemrev.5b00547

21. Li, Y.; Hari, D. P.; Vita, M. V.; Waser, J. Angew. Chem., Int. Ed. 2016, 55, 4436-4454. doi:10.1002/anie.201509073

22. Merritt, E. A.; Olofsson, B. Angew. Chem., Int. Ed. 2009, 48, 9052-9070. doi:10.1002/anie.200904689

23. Liu, C.; Yi, J.-C.; Liang, X.-W.; Xu, R.-Q.; Dai, L.-X.; You, S.-L. Chem. - Eur. J. 2016, 22, 10813-10816. doi:10.1002/chem.201602229

24. Caramenti, P.; Nicolai, S.; Waser, J. Chem. - Eur. J. 2017, 23, 14702-14706. doi:10.1002/chem.201703723

25. Caramenti, P.; Waser, J. Helv. Chim. Acta 2017, 100, e1700221. doi:10.1002/hlca.201700221

26. Grenet, E.; Waser, J. Org. Lett. 2018, 20, 1473-1476. doi:10.1021/acs.orglett.8b00337

27. Wu, B.; Wu, J.; Yoshikai, N. Chem. - Asian J. 2017, 12, 3123-3127. doi:10.1002/asia.201701530

28. Kwak, J.; Kim, M.; Chang, S. J. Am. Chem. Soc. 2011, 133, 3780-3783. doi:10.1021/ja111670s

29. Smout, V.; Peschiulli, A.; Verbeeck, S.; Mitchell, E. A.; Herrebout, W.; Bultinck, P.; Vande Velde, C. M. L.; Berthelot, D.; Meerpoel, L.; Maes, B. U. W. J. Org. Chem. 2013, 78, 9803-9814. doi:10.1021/j0401521y 


\section{License and Terms}

This is an Open Access article under the terms of the Creative Commons Attribution License

(http://creativecommons.org/licenses/by/4.0), which permits unrestricted use, distribution, and reproduction in any medium, provided the original work is properly cited.

The license is subject to the Beilstein Journal of Organic Chemistry terms and conditions:

(https://www.beilstein-journals.org/bjoc)

The definitive version of this article is the electronic one which can be found at:

doi:10.3762/bjoc.14.102 